\title{
Anthropology speaks to medicine: the case HIV/AIDS in Africa
}

\author{
Brodie Ramin*
}

\section{INTRODUCTION}

It is exceedingly rare for medical doctors and anthropologists to sit down and exchange ideas, even about an issue as important as the global HIV/AIDS epidemic. Does that mean that anthropologists have no knowledge of value to add to the epidemiological and biomedical understanding of the epidemic? This paper asserts that, despite the general neglect of anthropology by the biomedical and public health sciences, anthropology as a discipline has contributed valuable concrete knowledge that has enriched the epidemiological and biomedical understanding of the HIV/AIDS epidemic.

The paper argues that two schools of competing anthropological thought have contributed to this knowledge base. The first school is comprised of what will be called traditional anthropologists. These are classically trained anthropologists who see their role as adding socio-cultural depth to biomedical and epidemiological understandings of the HIV/AIDS epidemic. The second school stands for anthropological change. This group of political economy (PE) anthropologists argues that anthropology's 'special understanding' of society is not of primary relevance to understanding HIV/AIDS, as it is the political and economic structure in which individuals act that shapes their behaviour. This school proposes structural violence, the notion that societal structures such as racism, sexism and inequality cause direct and indirect harm to individuals, as the principal perspective for understanding HIV/AIDS ${ }^{1}$.

The paper examines anthropology's contribution to our understanding of HIV/AIDS and sexuality, gender, risk groups, and behaviour change strategies. The paper argues that while the $\mathrm{PE}$ anthropologists provide an extremely valuable perspective, their approach does not

\footnotetext{
* To whom correspondence should be addressed: Brodie Ramin Mailing: 2402-38 Elm Street, Toronto, ON, M5G 2K5, Canada Email: brodie.ramin@utoronto.ca
}

capitalize on anthropology's comparative advantage (a rich understanding of the local cultural context) and therefore risks ignoring an important level of anthropological analysis - the local culture. Thus both types of anthropological knowledge have contributed to our understanding of HIV/AIDS, and without this knowledge, clinicians and public health practitioners would lack our current nuanced understanding of the epidemic.

The focus of the paper is on the HIV/AIDS epidemic in sub-Saharan Africa specifically as Africa is home to 64 percent of all people living with HIV (1). While UNAIDS asserts that "[t]here is no such thing as the 'African' epidemic'" because there is a tremendous diversity across the continent in patterns of HIV infection, there are nonetheless certain commonalities found across sub-Saharan Africa (2). First, both aggregate prevalence and incidence are the highest in the world, with profound human and socio-economic ramifications. Second, despite recent strides forward, treatment rates remain the lowest in the world, with an estimated treatment coverage of fifteen percent (1). Third, the epidemic occurs alongside a number of macro-level social shocks such as wars, macroeconomic crises, other infectious disease epidemics, and high levels of political instability $(3,4,5,6)$.

\section{THEORETICAL AND HISTORICAL BACKGROUND}

Manderson traces anthropology's interest in disease to the discipline's "professionalization as an applied science, the interest of other public health scholars in anthropological methods and theories, and the

1 The author recognizes that there is no such person as a 'traditional anthropologist' and that PE anthropologists may equally use their traditional disciplinary tools. The classification is merely an attempt to present a stylized representation of two dissimilar approaches to anthropological understandings of HIV/AIDS. 
involvement of anthropologists in international health programs of multilateral organizations and bilateral aid programs" (7). Building on anthropologists' earlier work with public health issues, the social science study of AIDS in Africa has required "the efforts of both anthropologists sensitive to public health, biomedical and non-Western healing issues, and anthropologists who seek to analyze the AIDS epidemic as they would any other phenomenon in the field" (8). Manderson evokes a common theme of both schools of anthropology by asserting that anthropological involvement has ensured that "some account is taken of local knowledge, cultural influence on the patterns of disease, and structural barriers to good health" (7).

We can identify four stylized phases of anthropological research into HIV/AIDS in Africa since the onset of the epidemic:

1) Anthropologists as Handmaidens: The Biomedical Paradigm;

2) Anthropologists as Cultural Experts: The Community Paradigm;

3) Anthropologists as Political Economists: The Structural Violence Paradigm;

4) The Future: An Anthropological Synthesis (9).

During the Handmaiden period, anthropologists supported biomedical research without challenging the traditional public health approach. This early paradigm was characterized by a heavily biomedical emphasis and a largely individualistic bias in understanding HIV/AIDS $(8,9)$.

In the Cultural Expert phase, there was a move away from individual-centric understandings of the epidemic. By the late 1980s it had become clear that a far more complex set of social, structural, and cultural factors mediate the structure of risk in every population group, and that the dynamics of individual psychology could not be expected to fully explain changes in sexual conduct without taking these broader issues into account (10). During the early 1990s, there was a growing focus on the interpretation of cultural meanings as central to a fuller understanding of both the sexual transmission of HIV/AIDS in different social settings and the potential to respond to HIV/AIDS through the design of more culturally appropriate prevention programs (11).

In the Political Economist phase, anthropological literature on HIV/AIDS began to increasingly focus on the linkages between local sociocultural processes that create risk of infection and global political economy $(10,11,12,13,14)$. Farmer, a central figure in the structural violence school, is vituperatively critical of the earlier anthropological emphasis on cultural phenomena at the expense of political economy. He attributes these omissions of the structural and economic causes of HIV/AIDS transmission to "the ways in which anthropology 'makes it object"' (14). Farmer recounts that

Animal sacrifice, zoophilia, ritualized homosexuality, scarification, and ritual beliefs all figure prominently in the early anthropology of AIDS. The only problem was that none of this had any onstrable relevance to HIV transmission or AIDS outcomes, and claims to the contrary were eventually revealed to be mistaken (14).

The HIV/AIDS epidemic, Farmer argues, requires broad biosocial approaches emphasizing structural forces such as racism, sexism and inequality, of which structural violence is the pre-eminent model (14).

Castro and Farmer propose structural violence as a conceptual framework for understanding the HIV/AIDS epidemic $(12,15)$. They argue that societies are shaped by large-scale social forces such as racism, sexism, political violence, poverty, and other social inequalities that are rooted in historical and economic processes (12). These forces, which together define structural violence, "sculpt the distribution and outcome of HIV/AIDS" (Ibid.). As an example, consider Schoepf's observation that one consequence of the economic crisis of the 1980s was a proliferation of multiple partner strategies, as poverty forced women to exchange sexual favors for financial support (4). With the onset of AIDS, "what once appeared to be a survival strategy has been transformed into a death strategy" (4) as "[m]acrolevel crisis generates conditions for microlevel dislocation" (16). We thus see the power of Farmer's observation that: "fundamentally social forces and processes come to be embodied as biological events" $(14,17)$.

Linking HIV/AIDS and structural forces, such as poverty, is critical to achieving effective prevention and treatment strategies. This is because the links between disease and poverty are profound though often ignored. In a major report on AIDS as a Development Issue, Collins and Rau argue that it is "commonplace for HIV/AIDS programme managers to acknowledge poverty as a causative factor, but to then say that 'poverty' is beyond the scope of their programmes" (18).

Thus by continually emphasizing poverty and its associated structure of inequality, PE anthropologists provide a very powerful policy proposal: poverty reduction should be our central goal $(14,19)$. The whole of anthropology, however, cannot focus on poverty reduction, as that would be poor use of anthropology's comparative advantage, which leads us to our next topic, sexuality.

\section{SEXUALITY AND HIV/AIDS}

Writing in 1932, Malinowski observed a 'surfeit of sex' in anthropology. "I alone," he confessed, "have to plead guilty to four books on the subject, two of which have the word sex on the title-page" (20). After 
Malinowski, however, sexuality was given scant attention by social scientists until the AIDS epidemic provoked a renewed wave of research (21).

At the outset of the epidemic and even into the 1990s, the non-anthropological literature on HIV/AIDS contained sweeping statements about a special 'African sexuality,' based on traditional marriage patterns different from those of Europe and Asia (11). A common theme in early HIV/AIDS literature posited that the spread of the AIDS epidemic in sub-Saharan Africa was related to multi-partner sexual relations (22).

Anthropologists were employed to explain this hypothesis. Some early studies reported that sexuality outside of marriage is not disapproved of strongly in certain African societies $(22,24)$. Such research was not without its critics at the time, and ironically the notion that multiple sexual partners is more common in developing than developed countries was reversed by a 2006 epidemiological review in the Lancet which showed the opposite pattern (25).

A major theme of the critiques of early sexuality studies has been their emphasis on individual agency, the notion that individuals are able to make free and unconstrained decisions regarding their sexual behaviour. Since the 1990s, anthropological research has suggested that the range of factors influencing the construction of sexual realities is far more complex than previously perceived (16). With the rise of the structural violence paradigm, it has become more widely espoused that, as with all behaviour, not just cultural, but also structural, political, and economic factors shape sexual experience to a far greater extent than has previously been understood $(26,27)$. In particular, research has emphasized that political and economic factors have played a key role in determining the shape and spread of the epidemic and has further emphasized that these same factors have been responsible for many of the most complex barriers to effective AIDS prevention programs (10). This research has been important in changing our understanding of who is and is not at risk from HIV/AIDS, a debate addressed below.

\section{CONCEPTUALIZATIONS OF RISK GROUPS}

A major contribution of anthropological research to our understanding of HIV/AIDS came through the enhanced conceptualization of the much-abused term, 'risk groups.' World Development Report 1993 expressed mainstream public health thinking by arguing that "[h]igh-risk groups may include sex workers, migrants, members of the military, truck drivers, and drug users who share needles" (28). This view was widely held in the early 1990s and prostitutes were the first and most prominent identified risk group in Africa. Ugandan President Museveni asserted in November 1990 that "the main route of AIDS is through prostitution" (29).

Because of frequent associations between identified 'risk groups' and blame, epidemiological research was criticized for creating "scapegoated 'risk groups"' (8, 11). Such discourse was criticised by anthropologists for:

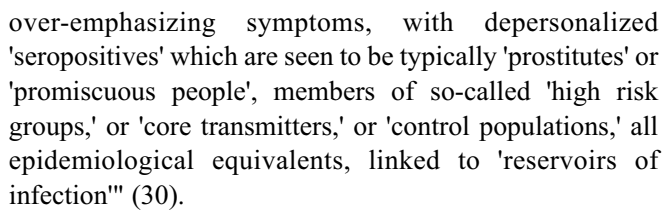

In opposition to such essentialist understandings, Schoepf and others argue that "there are no empirically bounded 'risk groups"', it is instead the behaviour of unprotected sex, rather than a particular kind of relationship that puts people at risk $(27,31,23)$. The categorization of empirically discrete risk groups was further undermined by anthropological research which emphasized the poor definitions of such groups, and the stigmatization which the earlier understanding of risk groups engendered. Moving away from the "trap of restricting our research to identified high-risk groups," anthropologists have been important in shifting the debate to the more useful concepts of 'vulnerable groups' and 'risk behaviours,' concepts which recognize that everyone is vulnerable to infection (32).

World Health Report 2004, which focused exclusively on HIV/AIDS, continued to employ the original understanding of risk groups, arguing that prevalence is higher among "people at higher levels of risk - sex workers, injecting drug users, men who have sex with men - and their sexual partners" (33). UNAIDS, by contrast, has taken up the discourse of vulnerable populations, which includes women and youth along with the original members of the high-risk groups. UNAIDS argues that "HIV/AIDS epidemics in many countries are concentrated in specific populations that are often marginalized and vulnerable to a broad range of health and psychosocial difficulties apart from, or in addition to, HIV/AIDS" (34). An important implication for prevention strategies is that as "AIDS thrives on exclusion ... including vulnerable people in all available responses is a way of increasing society's total resistance to the epidemic" (34). Building on the more recent understanding of vulnerable populations, we will now turn to the role of anthropology in understanding the gender dimension of the HIV/AIDS epidemic.

\section{GENDER AND HIV/AIDS}

Both traditional and PE anthropologists have made important contributions to our understanding of the gender dimension of the epidemic. As with all 'high risk groups,' women were implicitly blamed by the 
traditional understanding of the epidemic for spreading the disease (29). This is a problem which has not gone away. O'Neil warns that "[e]thnographic and epidemiological research has the potential for blaming and further stigmatizing women, if the research focuses exclusively on female sex workers as 'vectors"' (35). This has been observed in the case of women in Costa Rica, where prostitutes are "portrayed as the vectors, rather than agents/subjects/victims of disease" (36). In Northern Tanzania, Dilger interviewed informants who expressed feeling that women, whether married or unmarried, are 'greedy' for money and, therefore, have fast-changing sexual relations thatcan result in disease transmission (37).

Both the 'promiscuity' and 'vulnerability' of female sex workers have been singled out. However, sex workers are not unique in their problems pertaining to sexual negotiations. Anthropological studies in Southern Africa indicate that women, in general, are relatively powerless in sexual negotiations with men (38). Risk situations are omnipresent for women (39). Akeroyd links the sexual abuse of women to "cultural assumptions about relations between men and women and the subordinate (personal and often legal) status of women (8). Paradoxically, risks for young women increased as AIDS consciousness spread and men began to seek very young partners whom they assumed to be free of infection (4).

Rather than seeing women as vectors, a structural violence perspective allowed us to further understand their deep vulnerability due to economic, social and physical factors. Over a decade ago, World Development Report 1993 recognized that "[p]reventative efforts addressed to women, especially those of childbearing age, can protect both maternal and child health" (28). World Health Report 2004 asserted that women are already facing severe hardships resulting from "inequality, discrimination and victimization, and HIV/AIDS often exacerbates the hardships" (33).

Women often lack the agency to escape their vulnerability, predominantly because they are poor. It is poor women who are most susceptible to HIV infections, for gender alone does not define risk (18). Higher levels of female poverty is thus another compounding risk factor which has been identified (40, 41). The World Bank has emphasized that it "is important not simply to provide information on condoms but also to ensure their availability and to empower members of the core group, especially female sex workers, to use them" (28). UNAIDS similarly argues that the root causes of female vulnerability - their legal, social and economic disadvantages - must be addressed (2). Ultimately, this type of empowerment will require a reduction of poverty, but in the interim, anthropologists have identified a number of important behaviour change strategies.

\section{BEHAVIOUR CHANGES AND STRATEGIES}

Diverse and 'factually incorrect' understandings of the HIV/AIDS epidemic has made prevention an often insurmountable challenge in Africa. As UNAIDS argues, educational programmes need to take account of traditional belief and value systems, as well as popular mythologies that circulate amongst the population (34).

Anthropologists have helped ensure that education campaigns are, as far as possible, culturally appropriate. However, in the absence of widespread access to treatment, two major behaviour-change strategies which had little regard for local cultures have been employed: advocating abstinence/monogamy and promoting condom use $(4,5,42)$. Anthropologists recognized that both strategies face huge practical difficulties.

The idea that knowledge of risk does not necessarily translate into behaviour change is "as much a truism in public health as is the awareness in anthropology that what people say is no clear guide to what they do" (15, 43). Indeed, as HIV/AIDS continues to spread rapidly in Africa, one of the most difficult issues is the apparent disparity between people's knowledge and awareness of HIV/AIDS and the extent to which they take measures to protect themselves $(15,10)$. The policy implication of this disparity is that education about risk of infection is not sufficient as cultural determinants of health behaviours serve as important barriers to health behaviour change (31).

In the realm of behaviour change, few changes have faced more socio-cultural, economic, political and religious barriers than condom use. UNAIDS declares that "[c]ondoms are key to preventing the spread of HIV/AIDS" (34). Smith argues that while one may simply ask whether people have access to condoms, a more sophisticated manner of asking this question requires attention to issues of how sexual relations and condom use are negotiated within contexts of poverty, age and gender inequality, and other configurations of power that influence people's priorities and constrain their choices (15). Lyons identifies attitudes towards condom use in Uganda as ranging from 'condoms are not African,' 'condoms will promote promiscuity and moral lassitude,' 'condoms are a ploy to control our population size,' 'condoms kill women,' 'condoms are evil' to 'condoms will hinder the reconstruction of Uganda'" (29).

The most prominent barriers to condom use cited by traditional anthropological research are grounded in cultural norms. Setel's observation is representative: for many men and women, "the very definition of sex was to ejaculate into a women or to receive a man's sperm; using a condom was said to be 'dirtying oneself"' (44). 
Much anthropological research has observed that men in Africa frequently attach great importance to the notion of flesh-to-flesh sex, citing condoms for removing intimacy $(37,39)$. Smith recounts that "[m]any young people told me that suggesting condom use as protection from HIV/AIDS would be very difficult because it would imply either that one suspected one's partner was a carrier (or the kind of immoral person who could be a carrier) or that one's own sexual behaviour was sordid and risky" (15).

Invoking structural violence, Collins and Rau dismiss culture and argue that "[p]eople whose livelihood strategies expose them to a high risk of infection are, precisely because they are impoverished, less likely to take seriously...the threat of an infection that is fatal years from now" (p. 15). Others emphasize that risktaking behaviour is not solely an individual matter: it is caused ultimately by social and economic factors, and "influencing the underlying causes of the epidemic will do much more to control the spread of HIV infection than the best education or counselling programmes" (8). Education is important, but heeding and being able to act on advice are complex matters often beyond the control of an individual (Ibid). A number of anthropologists have recognized that the ultimate barrier to condom use is poverty. This is the case not only because of the direct costs of condoms $(34,39)$, but because of the broader culture of education, risktaking and self-preservation (15).

\section{CONCLUSION}

This paper has identified the major themes of knowledge anthropologists have contributed to our understanding of HIV/AIDS. From anthropological inquiry into sexuality in the African context, has come an awareness that individual choices and cultural norms encouraging 'promiscuity' cannot be exclusively blamed for spreading the epidemic. Our understanding of sexuality has also been deepened by embedding such behaviour in its political and economic context.

Regarding risk groups, anthropologists have been instrumental in shifting the discourse from empirically bounded 'risk groups' to more nuanced understandings of 'vulnerable groups' and 'risk behaviours.' We see in this sphere of knowledge the marriage between traditional anthropological analysis of behaviour with the PE anthropologists' emphasis of structures of risk and vulnerability. As with the risk group conceptualizations, the emphasis in the debate on HIV/AIDS and gender has shifted from women as 'vectors' to women as a vulnerable group.

Traditional anthropologists have ensured that behaviour change strategies accurately and sufficiently take into account the local culture. This has been especially important in terms of promoting behaviour change such as condom use, where cultural understandings such as the importance attached to flesh-to-flesh sex in certain African communities. The PE anthropologists have added, however that no amount of 'education' is enough, due to structural factors constraining and shaping people's behaviour. We can expect anthropologists to make important contributions to new debates surrounding male circumcision, which has been deemed efficacious at reducing HIV transmission, as well as microbicides, which may be shown to be efficacious in the near future (45).

In closing, it is not appropriate for the medical community to doubt the contributions of anthropology to the public health understanding of, and limited successes in the fight against, the HIV/AIDS epidemic. Setel cautions that "the formal health care sector can only add its voice to a social and cultural environment that already has its own very powerful epistemology of AIDS" (44). Thus broader social change grounded in anthropology is invaluable. Castro calls for anthropologists to act as 'advocates' for HIV patients and the poor generally (46). It is precisely through the synthesis of their traditional tools with a broader understanding of structural violence that anthropologists act, in conjunction with health care professionals, as advocates for HIV/AIDS patients.

\section{ACKNOWLEDGEMENTS}

I would like to thank Dr. Brian Cornelson of the University of Toronto for reviewing an earlier draft of this manuscript. I would also like to thank Melissa Vyvey for her support and guidance with all my work.

\section{REFERENCES}

1. UNAIDS. Report on the Global AIDS Epidemic. Geneva: UNAIDS; 2006.

2. UNAIDS. Reports on the global AIDS epidemic. Geneva: UNAIDS; 2004.

3. Chikwendu E. AIDS/HIV-When the State Fails: NGOs in Grassroots AIDS Care. Dialectical Anthropology 2004; 28 : 245-259.

4. Schoepf BG. Women, AIDS, and Economic Crisis in Central Africa. Canadian Journal of African Studies 1988; 22(3): 625644

5. G reen EC. The Anthropology of Sexually Transmitted Disease in Liberia. Social Science \& Medicine 1992; 35(12):1457-1468.

6. Van de Walle N. African economies and the politics of permanent crisis, 1979-1999. Cambridge: Cambridge University Press; 2003.

7. Manderson L. Applying medical anthropology in the control of infectious disease. Tropical Medicine and International Health 1998; 3(12): 1020-1027.

8. Akeroyd AV. Sociocultural Aspects of AIDS in Africa: Occupational and Gender Issues. In: Bond G, Kreniske J, Susser I., Vincent J, eds. AIDS in Africa and the Caribbean. Boulder, CO: Westview Press; 1997: 11-32.

9. Bond G, Vincent J. AIDS in Uganda: The First Decade" in AIDS 
in Africa and the Caribbean. In: Bond G, Kreniske J, Susser I., Vincent J, eds. AIDS in Africa and the Caribbean.Boulder, CO: Westview Press; 1997: 85-97.

10. Parker R. Sexuality, Culture and Power in HIV/AIDS Research. Annual Review of Anthropology 2001; 30, 163-179.

11. Schoepf BG. International AIDS Research in Anthropology: Taking a Critical Perspective on the Crisis. Annual Review of American Anthropology 2001; 30: 335-361.

12. Castro A, Farmer P. Understanding and Addressing AIDSRelated Stigma: From Anthropological Theory to Clinical Practice in Haiti. American Journal of Public Health. 2005; 95(1): 53-59.

13. Farmer P. On Suffering and Structural Violence: A View from Below. Daedalus 1996; 125(1): 261-283.

14. Farmer, P. Infections and Inequalities: The Modern Plagues, London: University of California Press; 1999.

15. Smith, DJ. Imagining HIV/AIDS: Morality and Perceptions of Personal Risk in Nigeria. Medical Anthropology 2003; 22: 343372.

16. Schoepf BG. AIDS, Gender and Sexuality During Africa's Economic Crisis. In: Mikell G, eds. African Feminism: The Politics of Survival; Pennsylvania, PA: University of Pennsylvania Press; 1997: 310-333.

17. Fordham G. Moral Panic and the Construction of National Order. Critique of Anthropology 2001; 21(3): 259-316.

18. Collins J, Rau B. AIDS in the Context of Development. UNRISD Programme on Social Policy and Development. Paper Number 4. Geneva: UNRISD and UNAIDS; 2000.

19. World Health Organization. Macroeconomics and Health: Investing in Health for Economic Development. Geneva: World Health Organization; 2001.

20. Tuzin D. Sex, Culture and the Anthropologist. Social Science \& Medicine 1991; 33 (8): 867-874.

21. Herdt G. Sexual Cultures and Population Movement: Implications for AIDS/STDs. In: Herdt G, ed. Sexual Cultures and Migration in the Era of AIDS. Oxford: Clarendon Press; 1997: 1-21.

22. Caldwell, JC. et al (1997) "Mobility, Migration, Sex, STDs, and AIDS; An Essay on Sub-Saharan Africa with Other Parallels" In: Herdt G, ed. Sexual Cultures and Migration in the Era of AIDS. Oxford: Clarendon Press; 1997: 42-54.

23. Larson, A. The Social Epidemiology of Africa's Aids Epidemic. African Affairs 1990; 89 (354): 5-25.

24. Fredland, RA.. AIDS and Development: An Inverse Correlation?" The Journal of Modern African Studies 1998; 36(4): 547-568.

25. Wellings K, Martine C, Slaymaker E, Singh S, Hodges Z, Patel D, Bajos N. Sexual behaviour in context: a global perspective. The Lancet 2006; 368 (9548): 1706-1728.

26. Farmer P. AIDS and Accusations: Haiti and the geography of blame. Berkley: University of California Press; 1992.

27. Schoepf, BG. AIDS Action-Research with Women in Kinshasa, Zaire. Social Science \& Medicine 1993; 37 (11): 1401-1413.

28. World Bank. World Development Report 1993: Investing in Health. Washington, D.C.: World Bank; 1993.

29. Lyons, M. "The Point of View: Perspectives on AIDS in
Uganda. In: Bond G, Kreniske J, Susser I., Vincent J, eds. AIDS in Africa and the Caribbean. Boulder, CO: WestviewPress; 1997: 131-148

30. Seidel, G. The Competing Discourses of HIV/AIDS in SubSaharan Africa: Discourses of Rights and Empowerment vs. Discourses of Control and Exclusion. Social Science \& Medicine 1993; 36(3): 175-194.

31. McGrath, J. et al. Anthropology and AIDS: The Cultural Context of Sexual Risk Behaviour Among Urban Baganda Women in Kampala, Uganda" Social Science \& Medicine 1993; 36(4): 429-439.

32. Marshall, PA, Bennett LA. Anthropological Contributions to AIDS Research Medical Anthropology Quarterly 1990; 4(1):3-5

33. World Health Organization. World Health Report 2004: Changing History. Geneva: WHO; 2004.

34. UNAIDS. Report on the Global HIV/AIDS Epidemic. Geneva: UNAIDS; 2002.

35. O'Neil $\mathrm{J}$ et al. "Dhandra, dharma and disease: traditional sex work and HIV/AIDS in rural India. Social Science \& Medicine 2004; 59: 851-860.

36. Downe PJ. Constructing a Complex of Contagion: The Perceptions of AIDS Among Working Prostitutes in Costa Rica" Social Science \& Medicine 1997; 44(10): 1575-1583.

37. Dilger H. Sexuality, AIDS and the Lures of Modernity: Reflexivity and Morality among Young People in Rural Tanzania. Medical Anthropology 2003; 22: 23-52.

38. Wojcicki JM, Malala J. Condom use, power and HIV/AIDS risk: sex-workers bargain for survival in Hillbrow/Jouet Part/Berea, Johannesburg" Social Science and Medicine 2001; 53: 99-121.

39. MacPhail C, Campbell C. 'I think condoms are good but, adi, I hate those things': condom use among adolescents and young people in a South African township" Social Science \& Medicine 2001; 52: 1613-1627.

40. Kabeer N.Reversed Realities: Gender Hierarchies in Development Thought. London: Verso; 1994.

41. Sen AK. Gender and Cooperative Conflicts. In: Tinker I, ed. Persistent Inequalities, Oxford: Oxford University Press; 1990: 123-149.

42. Ingstad B. The Cultural Construction of AIDS and Its Consequences for Prevention in Botswana. Medical Anthropology Quarterly 1990; 4(1): 28-40.

43. Good B. Medicine, rationality, and experience: an anthropological perspective. Cambridge: Cambridge University Press; 1994.

44. Setel P. AIDS as a Paradox of Manhood and Development in Kilimanjaro, Tanzania. Social Science \& Medicine 1996; 43(8): 1169-1178.

45. Quinn TC. Circumcision and HIV transmission. Current Opinion in Infectious Diseases 2007; 20:33-38.46. Castro A. Anthropologists as Advocates. Anthropology News 2004 October: 9-11.

46. Castro A. Anthropologists as Advocates. Anthropology News 2004 October: 9-11.

Brodie Ramin (M. Phil, MD 2009) is a medical student at the University of Toronto with a strong interest in the health of marginalized populations in Canada and globally. Prior to medical school, Brodie studied international development and biology at McGill and development studies at Cambridge. Following medical school Brodie intends to pursue public health training and work on global public health issues in both practical and research fields. 